\title{
Modification of Superabsorbent Hydrogels for Industrial Wastewater Treatment
}

\author{
Md. Owaleur Rahman, ${ }^{1}$ Md. Abdul Halim, ${ }^{1}$ Anjan Deb, ${ }^{1}$ Shafi Ahmed, ${ }^{2}$ \\ Md. Wasikur Rahman, ${ }^{1}$ N. C. Dafader, ${ }^{3}$ S. M. Nur Alam, ${ }^{1}$ Shahjalal Khandaker, ${ }^{4}$ \\ and Md. Jahangir Alam ${ }^{1}$ \\ ${ }^{1}$ Department of Chemical Engineering, Jashore University of Science and Technology, Jashore 7408, Bangladesh \\ ${ }^{2}$ Department of Agro Product Processing Technology, Jashore University of Science and Technology, Jashore 7408, Bangladesh \\ ${ }^{3}$ Nuclear and Radiation Chemistry Division, Atomic Energy Research Establishment, Savar, Dhaka, Bangladesh \\ ${ }^{4}$ Department of Textile Engineering, Dhaka University of Engineering \& Technology, Gazipur 1707, Bangladesh
}

Correspondence should be addressed to Md. Jahangir Alam; jahangirche@gmail.com

Received 3 January 2022; Revised 30 January 2022; Accepted 31 January 2022; Published 14 February 2022

Academic Editor: Gyorgy Szekely

Copyright (c) $2022 \mathrm{Md}$. Owaleur Rahman et al. This is an open access article distributed under the Creative Commons Attribution License, which permits unrestricted use, distribution, and reproduction in any medium, provided the original work is properly cited.

\begin{abstract}
A breakthrough in superabsorbent hydrogel (SAH) preparation was studied in the current issue by blending potato starch and acrylic acid for wastewater treatment. Gamma irradiation source $\left({ }^{60} \mathrm{Co}\right.$ irradiation) was used to irradiate SAH from 1 to $10 \mathrm{kGy}$ dose at room temperature $\left(\sim 27^{\circ} \mathrm{C}\right)$. The swelling ratio, water absorption, equilibrium water content, and gel fraction properties of the hydrogel were investigated. The as-prepared hydrogel treated with KOH (THG) showed excellent absorption capacity but less mechanical stability compared to untreated hydrogel (UHG). The gel fraction of treated SAH was slightly lower in methanol, but the utmost in water at $5 \mathrm{kGy}$ infers the proper grafting of SAH at this point. The prepared SAH was characterized using scanning electron microscopy (SEM) and Fourier transform infrared (FTIR) to investigate the surface morphology and molecular interaction, respectively. Moreover, this study's focal point is to propose an alternative method to remove chromium and methylene blue by SAH from industrial wastewater. The $\mathrm{Cr}$ adsorption capacity of UHG was higher than that of THG because the proton's replacement is easier than that of K by Cr. On the other hand, THG was found to be more efficient in removing methylene blue from industrial wastewater due to the presence of an easily ionized group (-COOK) in SAH. Therefore, the hydrogel can be proposed as a potential superabsorbent to remove heavy metals and organic dyes from industrial wastewater.
\end{abstract}

\section{Introduction}

Hydrogels are three-dimensional cross-linked polymeric substances that can absorb water in an aqueous environment. Among various types of hydrogels, there is a particular category that can absorb water several hundred times its dry weight named superabsorbent hydrogels (SAHs). They can absorb and retain vast amounts of water even under high pressure or temperature because of the existence of several hydrophilic groups, e.g., $-\mathrm{OH},-\mathrm{COOH},-\mathrm{CONH}_{2}$, $\mathrm{CONH}$, and $-\mathrm{SO}_{3} \mathrm{H}$. SAH does not allow its substance to dissolve in water due to its grafted polymeric network
[1-6]. SAH has found extensive use mostly in the manufacturing of baby diapers, sanitary napkins, candles, composites and laminates, controlled drug delivery, filtration, fire-retardant gels, flood control, fragrance carriers, medical waste solidification, surgical pads, water-absorbent pads, wound dressings, in agricultural land as a soil conditioner and fertilizer, etc. [7].

Many types of preparation processes are available to prepare hydrogels of various categories. In general, hydrogels can be prepared by cross-linking of monofunctional and multifunctional monomers or by cross-linking of the copolymer, homopolymer in solution, and simultaneous 
copolymerization. The cross-linking process has two steps to complete. The first step is synthesizing the linear polymers in the absenteeism of agents, and the second step is crosslinking of the synthesized polymers using either chemical reagents or irradiation [8-10]. The radiation-induced polymerization technique is a modern, worldwide, ecofriendly concept. It can promote cross-linking in a wide range of polymers and copolymers without additives during the polymerization process. The chemical, physical, and mechanical properties can be improved by cross-linking of polymers [11], and the intensity of cross-linking is controlled by the radiation dose [12]. The cross-linked structure of the polymer is imperative for the packed column application. Additionally, the cross-linked polymer might form a more stable complex with metal ions due to its rigid network structure [13]. The use of the radiation polymerization technique has the following advantages: (i) ionizing radiation initiates radical polymerization at ambient temperature in the absence of chemical initiators [14, 15]; (ii) the initiation step of radiation polymerization is temperature-independent, and the overall activation energies are much smaller than in the chemically initiated process $[14,16]$; (iii) the resulting polymer is homogeneous and free from any impurities, and the molecular weight can be controlled by varying doses and dose rate $[14,17]$.

Adsorption among other water purification technologies is fast, low-cost, easy operation, and high efficiency without producing undesirable by-products $[18,19]$. Natural polymer-based hydrogels are revealed as nontoxic, environmentally friendly compounds, which treated as renewable or biologically degradable polymers with lower toxicity [20]. Monir et al. [21] prepared hydrogel from polyethylene oxide (PEO) and acrylic acid (AAc) blends by applying gamma radiation. Afroz et al. [4] prepared hydrogel by aqueous mixture blend of polyethylene oxide (PEO)/N,N-dimethylacrylamide (DMA) using gamma radiation. Sultana et al. [22] synthesized hydrogels from a dilute solution of carboxymethyl cellulose in the presence of mono- and divalent salts by applying gamma radiation. Dafader et al. [23-25] produced three different categories of hydrogels from acrylamide/HEMA, polyvinyl pyrrolidone/AAc, and cassava starch/AAc by graft copolymerization method using gamma radiation of different doses. Bhuyan et al. [26] prepared hydrogels from a blend of potato starch and AAc with gamma radiation and compared the properties with the addition of $\mathrm{NaOH}$ in the hydrogel and used only to remove dye. Recently, a few types of hydrogels, i.e., micelle-laden [27], scavenging nanocomposite [28], chitosan [29], and porous nanocomposite [30], are used for water treatment available in the open literature.

However, it has no extensive studies to remove chromium (Cr) and methylene blue (MB) by SAH from lather and textile industrial wastewater (IWW) collected from Savar industrial area, Bangladesh. Therefore, in this present study, potato starch and acrylic acid blends were used to get superabsorbent hydrogels (SAHs) which were irradiated with Co-60 gamma radiation. A number of them were prepared with the addition of alkali $(\mathrm{KOH})$ solution, and this is also a novelty of this study. The swelling ratio, water absorption, equilibrium water content, and gel fraction were measured and compared with $\mathrm{KOH}$-treated hydrogel (THG) and untreated hydrogel (UHG). The surface morphology and molecular interaction of $\mathrm{SAH}$ were investigated by scanning electron microscopy (SEM) and Fourier transform infrared (FTIR), respectively. Additionally, the development of an alternative method was established to remove chromium (Cr) and methylene blue (MB) by SAH from IWW.

\section{Experimental}

2.1. Chemicals. Potato starch was collected from SigmaAldrich, India. Acrylic acid and $\mathrm{KOH}$ pellets were purchased from Guangdong Guanghua Chemical Factory Co. Ltd., China, and Merck Private Co. Ltd., India, respectively. All chemicals were reagent grade and used without further purification.

2.2. Apparatus. Atomic Absorption Spectrophotometer (AAS) (model: AA-6800, supplied by SHIMADZU, Japan), Cobalt-60 gamma radiation source (model: GSCIE-11), Fourier transform infrared (FTIR) spectrophotometer (model: AIM-8800, supplied by SHIMADZU, Japan.), and scanning electron microscopy (SEM) (model: JSM-6490, JEOL) were employed for sample characterization.

\subsection{Preparation of Superabsorbent Hydrogel (SAH)}

2.3.1. Preparation of SAH from Starch and AAc Solution. $150 \mathrm{ml}$ distilled water and $20 \mathrm{~g}$ starch were mixed in a $400 \mathrm{ml}$ beaker and stirred with a magnetic stirrer under heating conditions until the dissolution of starch at $80^{\circ} \mathrm{C}$ for $30 \mathrm{~min}$. Then, the solution was cooled slowly until room temperature, and $30 \mathrm{ml}$ saturated acrylic acid was added to the beaker. The beaker was sealed with aluminum foil. The solution was stirred continuously (without heating) for 30 minutes to make a homogeneous mixture. Then, the solution contained in the glass test tubes was poured into polyethylene bags, and after pouring the samples, the polyethylene bags were sealed. Then, the solution was sent to a gamma radiation source for irradiation.

2.3.2. Preparation of $\mathrm{SAH}$ from Starch, $A A c$, and $\mathrm{KOH}$ Solution. To prepare a $3.86 \mathrm{M} \mathrm{KOH}$ solution, $50 \mathrm{ml}$ distilled water and $10.8 \mathrm{~g} \mathrm{KOH}$ were mixed in a $100 \mathrm{ml}$ reagent bottle. It was stirred with a glass rod until $\mathrm{KOH}$ dissolved in water. In the prepared starch solution, $\mathrm{KOH}$ solution was mixed with stirring for 20 minutes. Then, $30 \mathrm{ml}$ acrylic acid was added into the beaker and sealed with aluminum foil. The solution was stirred continuously for 30 minutes to get a homogeneous mixture. Then, the prepared solution was taken in several test tubes from beaker and poured into polyethylene bags, and after pouring the samples, the polyethylene bags were sealed. Then, the solution was sent to a gamma radiation source for irradiation by ${ }^{60} \mathrm{Co}$ source with radiation doses of $1,3,5,7$, and $10 \mathrm{kGy}$ at $6.8 \mathrm{kGy} / \mathrm{h}$ of radiation dose rate. The obtained SAHs were 


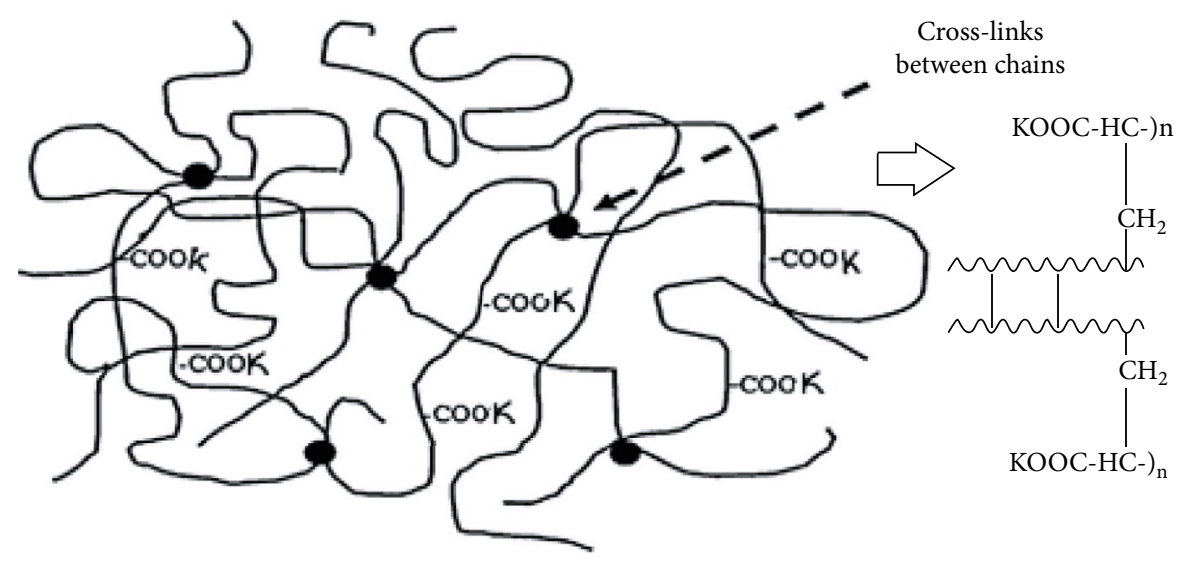

FIGURE 1: Schematic view of a cross-linked polymer network.

(1)

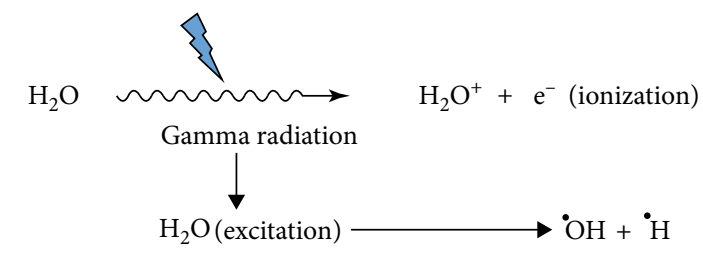

(2).

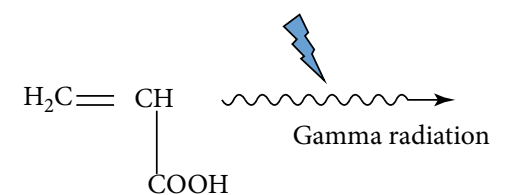

Acrylic acid

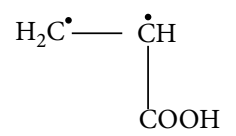

Acrylic acid free radical

(3).

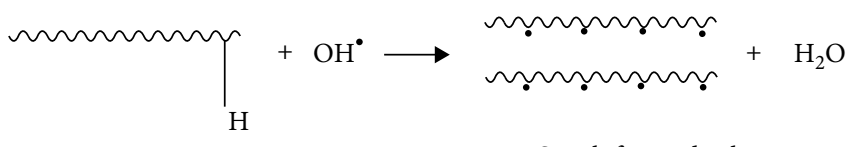

Starch chain

Starch free radical

(4).

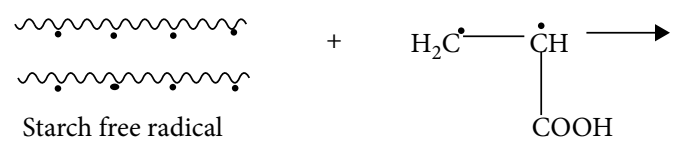

Acrylic acid free radical
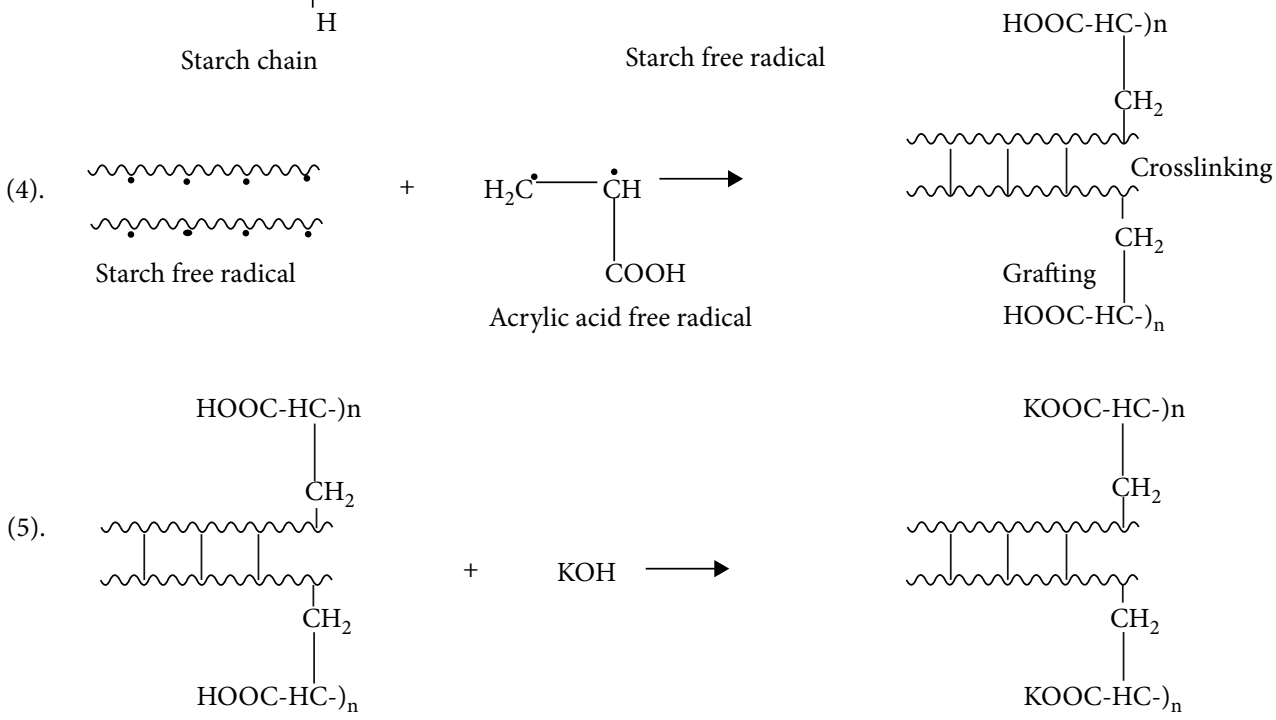

FIgURE 2: Possible grafting and cross-linking reaction mechanism of SAH.

cylindrical. They were cut down into small pieces, dried in air, and then kept in a vacuum oven to make gels of constant weight. The yield of hydrogel production was calculated as $93 \%$ by weight basis.
2.4. Determination of Gel Content. The dried hydrogel samples were kept inside the distilled water for $24 \mathrm{~h}$ to remove the soluble fraction. Then, the gel samples were taken out and dried to a constant weight under vacuum to 


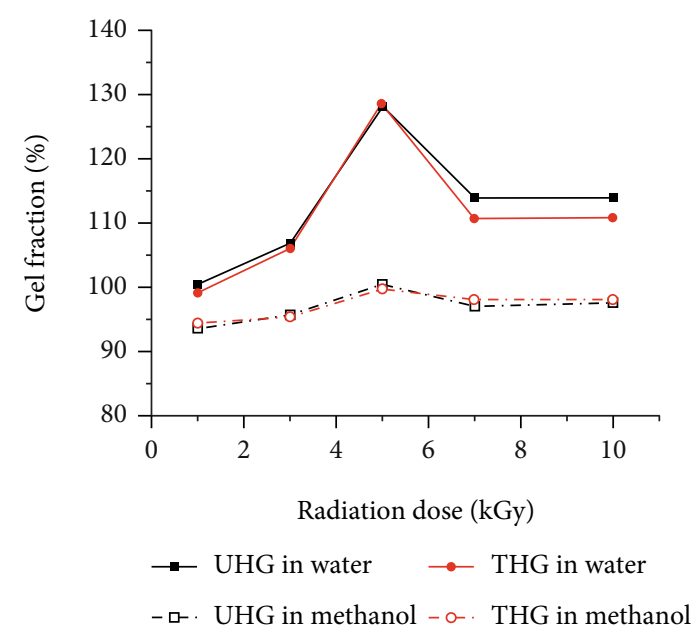

FIgURE 3: Gel fraction of THG and UHG in water and methanol.

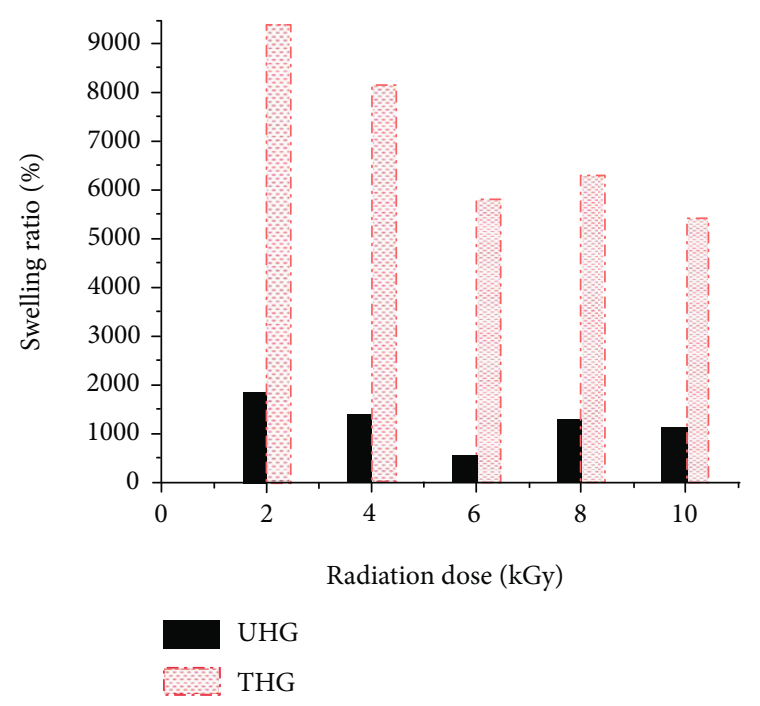

FIGURE 4: The swelling ratio of THG and UHG with radiation dose.

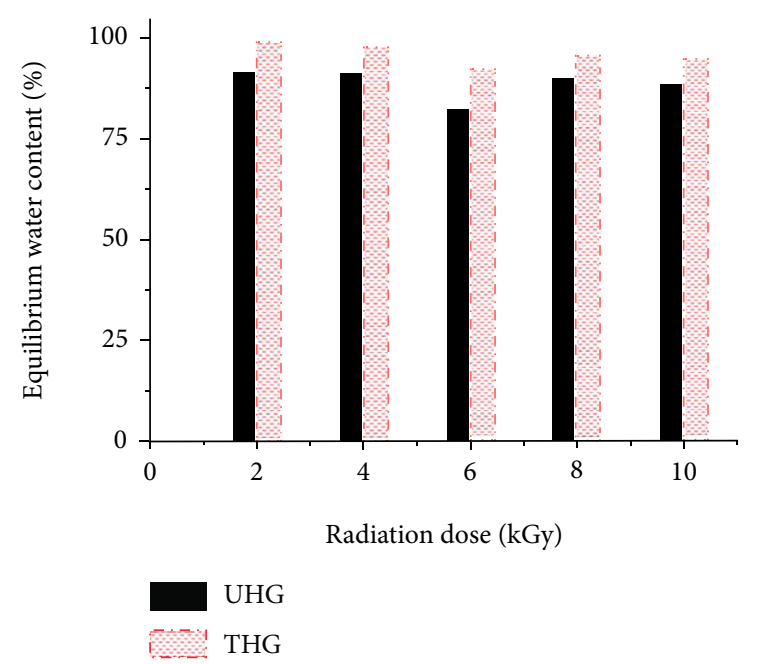

FIGURE 5: The equilibrium water content of THG and UHG with radiation dose. determine the insoluble content in the samples gravimetrically.

$$
\text { Gel content }(\%)=\left[\frac{W_{1}}{W_{0}}\right] \times 100,
$$

where $W_{1}$ is the weight of dry gel after extraction in distilled water and $W_{0}$ is the initial weight of dry gel.

2.5. Determination of the Swelling Ratio. SAH samples dried to a constant weight were immersed in distilled water until maximum swelling was obtained at room temperature $\left(\sim 27^{\circ} \mathrm{C}\right)$. The prepared hydrogel contains cross-linking polymer network that increases its volume by absorbing water. The temperature of water affects the internal energy and entropy of hydrogel, which leads to the penetration of water into the hydrogel, which means swelling ratio. In the present study, the water temperature was maintained at around $25^{\circ} \mathrm{C}$ throughout the experiment. The swollen samples were removed with distilled water and weighed after removing the surface water with soft tissue paper. The experiment was repeated three times for each sample, and the average weight of the swollen sample was determined. The swelling ratio was calculated as follows:

$$
\text { Swelling ratio }=\frac{\left[W_{2}-W_{1}\right]}{W_{1}},
$$

where $W_{1}$ and $W_{2}$ are the weight of the dried and swelled gel, respectively.

2.6. Determination of Equilibrium Water Content. The gel sample was dried to a constant weight and was kept in distilled water at room temperature. Swelling of the gel was continued to reach the constant weight and weighed after removing any surface water with tissue paper. The equilibrium water content was calculated as follows:

$$
\text { Equilibrium water content }(\%)=\left(\frac{\left[W_{2}-W_{1}\right]}{W_{2}}\right) \times 100,
$$

where $W_{1}$ and $W_{2}$ are the weight of dried gel and gel after water absorption, respectively.

2.7. Determination of Water Absorption. After immersing the hydrogel samples in distilled water at room temperature, the samples were periodically weighed for blotting excess surface water on filter paper. The water absorption of the samples was calculated as follows:

$$
\text { Water absorption }(\%)=\left(\frac{\left[W_{t}-W_{1}\right]}{W_{1}}\right) \times 100 \text {, }
$$

where $W_{1}$ are $W_{t}$ are the weight of dried and swelled gel at time $t$, respectively.

2.8. Determination of Chromium Adsorption. Atomic Absorption Spectrometry (AAS) is a prevalent and reliable technique for detecting metals and metalloids in 


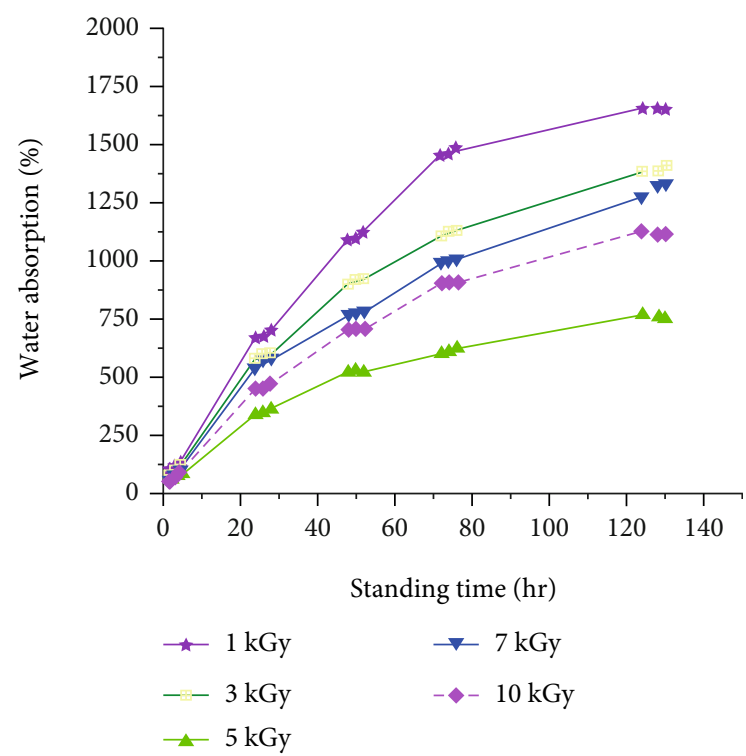

Figure 6: The effect of radiation dose and standing time on water absorption of UHG.

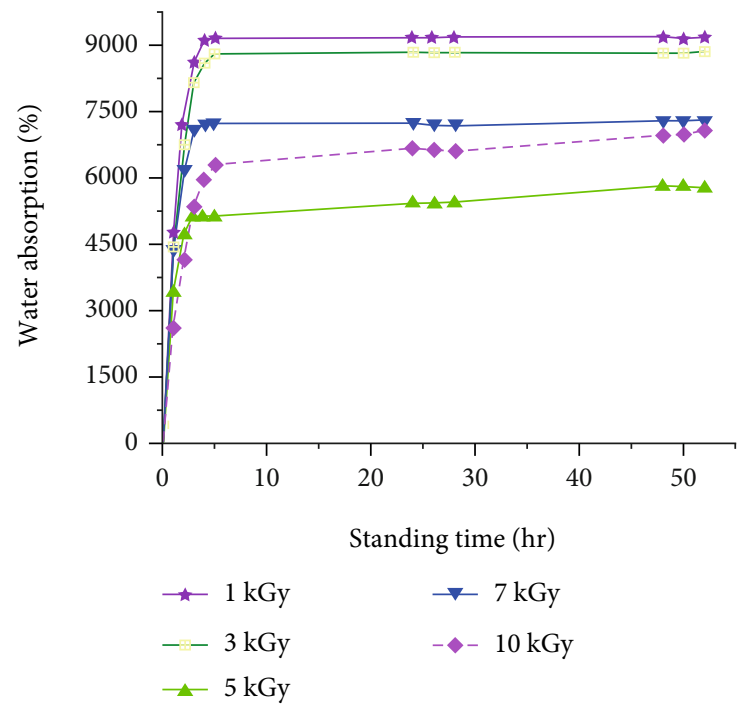

FIgURE 7: Effect of radiation dose and standing time on water absorption of THG.

environmental samples. The total chromium content in water and SAH samples was measured by Flame Atomic Absorption Spectrometry. At first, a typical set of standard calibration curves with good linear regression and better relative standard deviation was attained. The absorption capacity of SAH was determined by chromium adsorption as follows:

$$
\text { Metal adsorption capacity }=\frac{\left(V\left(C_{1}-C_{2}\right)\right)}{W},
$$

where $V$ is the volume of the chromium solution in liter, $W$ is the weight of SAH in gram, $C_{1}$ is the concentration of

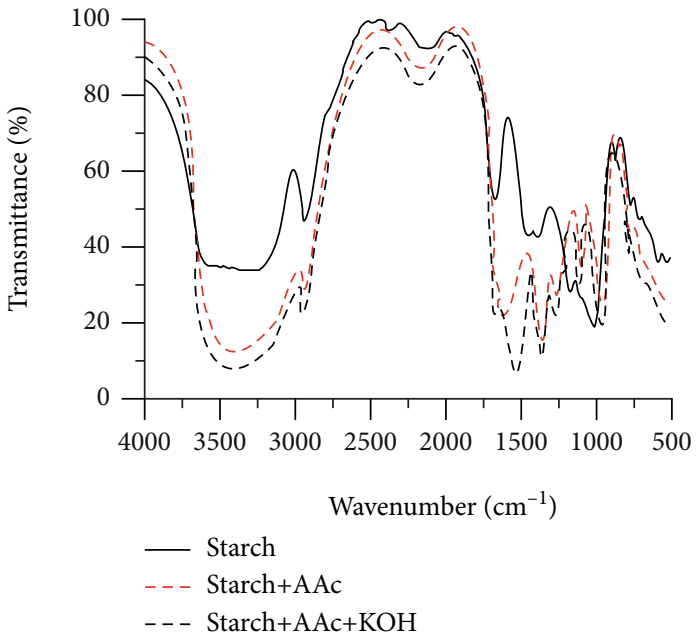

FIGURE 8: FTIR spectra of hydrogels.

Cr solution before adsorption (ppm), and $C_{2}$ is the concentration of $\mathrm{Cr}$ solution after adsorption (ppm).

2.9. Determination of Methylene Blue Dye Adsorption. Water-soluble dye methylene blue solution was prepared by dissolving the dye in deionized water. The $\mathrm{SAH}$ was added into the dye solution, and the concentration of dye solution was $20 \mathrm{ppm}, 40 \mathrm{ppm}$, and $60 \mathrm{ppm}$. The amount of residual dye in an aqueous solution was determined by UV-visible spectroscopy periodically. The absorption capacity of SAH was determined for methylene blue adsorption as follows:

$$
\text { Dye absorption capacity }=\frac{\left(L\left(C_{1}-C_{2}\right)\right)}{M},
$$

where $L$ is the volume of the dye solution in liter, $M$ is the weight of SAH in gram, $C_{1}$ is the concentration of dye solution before adsorption ( $\mathrm{ppm}$ ), and $C_{2}$ is the concentration of dye solution after adsorption (ppm).

\section{Results and Discussions}

3.1. The Mechanism of the Reaction. Gamma radiation leads to cross-linking in the starch matrix. The impact of gamma radiation on starch was reported before by [31]. They provide insight into the improvement of the physical and cross-linking properties by gamma radiation. Figure 1 shows the schematic view of a cross-linked polymer network. In the radiated solution, three reactive species were formed in water as hydrated electrons, hydroxyl radicals, and hydrogen radicals. The free radicals generated in the starch molecule (amylopectin) were observed after exposure to the solution with radiation treatment. In the aqueous blend of starch and AAc with the use of radiation, the free radicals formed in acid react with radiated starch to get a long-chain graft structure of hydrogels shown in Figure 2. The grafting process of acrylic acid onto potato starch was carried out using a radiation source, and a polymeric network of negatively charged $-\mathrm{COO}^{-}$groups was generated. Finally, the alkali- (KOH-) treated SAH was carried 
TABLE 1: Characteristic bands of different functional groups in hydrogels.

\begin{tabular}{lcr}
\hline Functional group & Frequency range $\left(\mathrm{cm}^{-1}\right)$ & Reference $\left(\mathrm{cm}^{-1}\right)$ \\
\hline -OH stretching of starch & 3450 & $3423[26]$ \\
C-O-C stretching of starch & $1020-1170$ & $1022-1161[26]$ \\
C-H stretching of absorption & 2950 & $294[26]$ \\
C=O stretching of the carboxyl group of AAc & 1720 & $171[26]$ \\
- COOK in SAH & 1550 & $153[33]$ \\
\hline
\end{tabular}

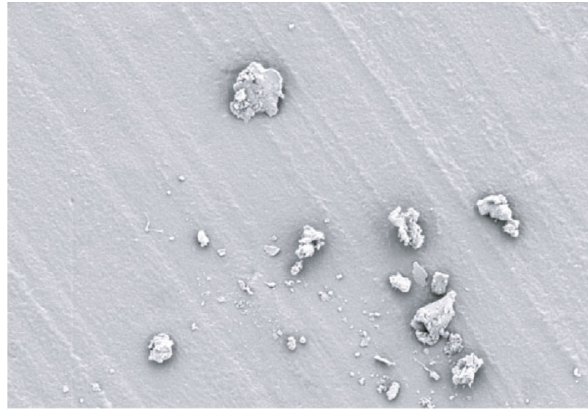

(a)

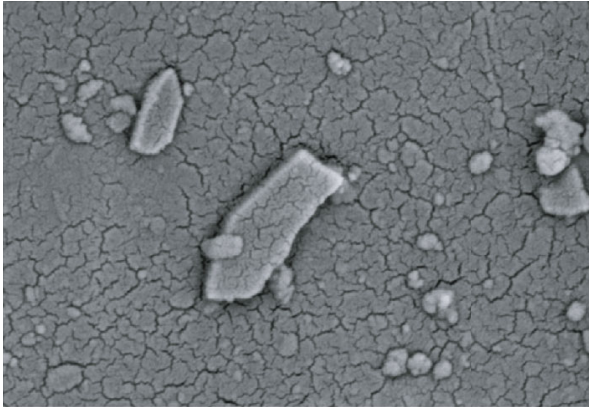

(b)

Figure 9: SEM images of SAH: (a) UHG and (b) THG.

out by the -COOK group by replacing the proton with potassium ions as shown in Figures 1 and 2.

3.2. Effect of Radiation Dose and $\mathrm{KOH}$ on Gel Fraction. The $\mathrm{KOH}$-treated hydrogel (THG) and untreated hydrogel (UHG) were prepared by gamma radiation at different doses, and the as-prepared hydrogels were dissolved in two different solutions of pure methanol and water. The results obtained from the experiment are presented in Figure 3. The gel fraction of SAH increased with grafting with radiation dose in a specific value up to $5.0 \mathrm{kGy}$. Above the radiation $5.0 \mathrm{kGy}$, the gel fraction shows a decreasing trend due to the degradation of molecules. The gel fraction of $\mathrm{SAH}$ is almost $15 \%$ better in water than that of methanol. In literature, the gel fraction was measured after removing the dissolved parts from solvent-immersed hydrogel as similar studies reported elsewhere [21, 22].

3.3. Effect of Radiation Dose and $\mathrm{KOH}$ on Swelling Ratio. The effect of radiation dose on the swelling ratio of treated (THG) and untreated hydrogels (UHGs) was observed in Figure 4. The swelling ratio decreases with increasing radiation dose, due to an increase in cross-linked density and lower most value at $5.0 \mathrm{kGy}$. This might be due to the proper grafting of $\mathrm{SAH}$ at $5.0 \mathrm{kGy}$ implying the optimum radiation dose. The swelling ratio of THG was found to be about 5.0 times better than that of UHG due to the higher water absorption capacity of $\mathrm{KOH}$-treated SAH. The hydrophilicity of the potassium carboxylate group (-COOK) is higher than that of the carboxyl group $(-\mathrm{COOH})$. Bhuyan et al. and Lou et al. [26, 32] measured the swelling ratio of $\mathrm{NaOH}$-treated hydrogels and found a better swelling ratio of THG than that of UHG.
3.4. Effect of Radiation Dose and $\mathrm{KOH}$ on Equilibrium Water Content. Figure 5 shows the effect of radiation dose and $\mathrm{KOH}$ on the equilibrium water content. It can be found that the equilibrium water content decreases with increased radiation dose because more grafting ability implies less amount of water absorbed. A similar phenomenon was also reported in [22]. The minimum equilibrium water content was found at $5.0 \mathrm{kGy}$ for excellent grafting. In addition, the equilibrium water content was found $8 \%$ better in THG than UHG due to higher water absorption capacity. Nevertheless, the THG was easily broken after water absorption because of its less mechanical stability of it.

3.5. Effect of Radiation Dosage on Water Absorption of UHG. The impact of the radiation dose on water absorption of UHG is presented in Figure 6. The patterns of all studied data obtained from water absorption showed uphill trends withstanding time. The water absorption capacity of SAH was maximum at $1.0 \mathrm{kGy}$ radiation dose and gradually decreased until $10.0 \mathrm{kGy}$ except at $5.0 \mathrm{kGy}$. The lowest water absorption occurred at $5.0 \mathrm{kGy}$ due to better cross-linking at this point, and above it is the initiation of degradation of molecules of SAH. Considering other doses, the water absorption capacity of SAH reduces in the periodic order. The established view of the point is that the cross-linking increases with the increase of radiation dosage as well as void spaces in the polymer network reduced for free water entrance and imply low water absorption capacity [23].

3.6. Effect of Radiation Dosage on Water Absorption of THG. The effect of radiation dose on water absorption of THG is shown in Figure 7. Water absorption capacity of the alkalitreated sample (THG) increases sharply withstanding time from 1.0 to $5.0 \mathrm{~h}$ and becomes constant after a pick point 


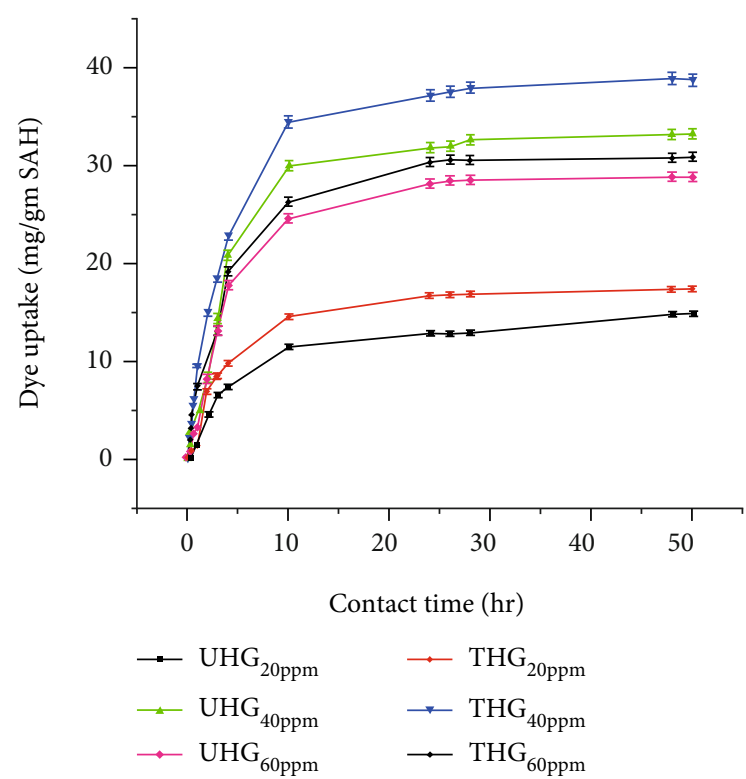

FIGURE 10: The effect of contact time on the removal of methylene blue dye.

TABLE 2: Characteristics/efficiency value of SAH at $5.0 \mathrm{kGy}$.

\begin{tabular}{lccc}
\hline \multirow{2}{*}{ Property/performance } & \multirow{2}{*}{ Unit } & THG & UHG \\
\hline Gel fraction & $\%$ & 128.43 & 128 \\
Swelling ratio & $\%$ & 5871.5 & 570.65 \\
Equilibrium water content & $\%$ & 92.5 & 82.38 \\
Water absorption & $\%$ & $5798.61_{\min }$ & $755.06_{\min }$ \\
MB removal at $40 \mathrm{ppm}$ & $\mathrm{mg} / \mathrm{g}$ & $38.77_{\max }$ & $33.31_{\max }$ \\
Cr removal at $40 \mathrm{ppm}$ & $\mathrm{mg} / \mathrm{g}$ & $5.93_{\max }$ & $10.13_{\max }$ \\
\hline
\end{tabular}

min: minimum; max: maximum.

beyond $5.0 \mathrm{~h}$. However, the water absorption of the gels showed utmost at $1.0 \mathrm{kGy}$ radiation dose due to lack of proper cross-linking and lowest at $5.0 \mathrm{kGy}$ because of desired cross-linking. Moreover, the water absorption capacity of the treated gels was observed to be lowest at $5.0 \mathrm{kGy}$ due to the deficiency of void space in the system.

3.7. FTIR Analysis of SAH. FTIR analysis can present the molecular interaction of potato starch/AAc blend to form a hydrogel. Figure 8 presents the infrared spectra of potato starch, starch/AAc, and starch/AAc/KOH blended hydrogel. The peaks observed around $3450 \mathrm{~cm}^{-1}$ and $1020-1170 \mathrm{~cm}^{-1}$ can be attributed to the $\mathrm{O}-\mathrm{H}$ stretching and $\mathrm{C}-\mathrm{O}-\mathrm{C}$ skeletal vibration of starch. The absorption peak at $2950 \mathrm{~cm}^{-1}$ corresponds to $\mathrm{C}-\mathrm{H}$ stretching of the acrylate unit and starch, while the bands at 1395 and $1265 \mathrm{~cm}^{-1}$ correspond to the angular deformation of $\mathrm{C}-\mathrm{H}$. The peak at $1720 \mathrm{~cm}^{-1}$ can be ascribed to the $\mathrm{C}=\mathrm{O}$ stretching of the carboxyl group of AAc. In addition, peak at $1550 \mathrm{~cm}^{-1}$ corresponds to $-\mathrm{COOK}$, which is absent in the spectra of starch/AAc and pure starch. This result indicates the interaction of AAc with starch. The FTIR spectra are listed and compared with previous work in Table 1.

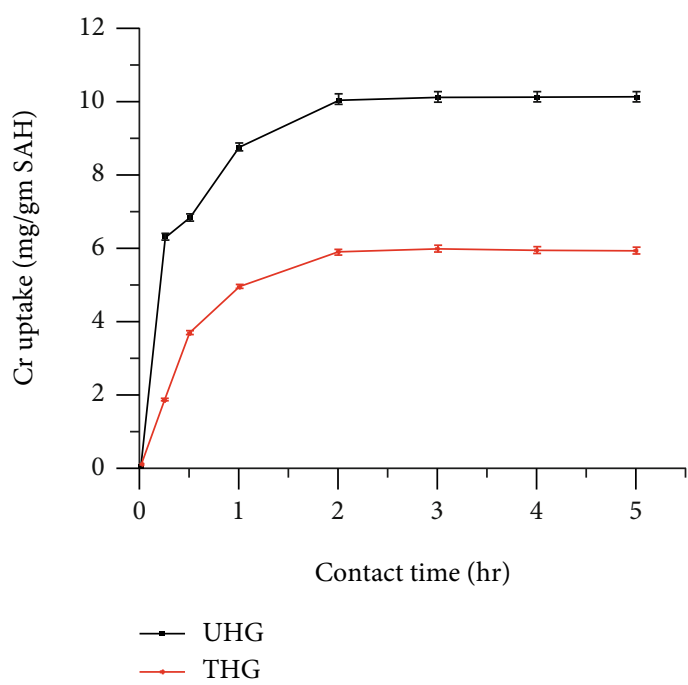

FIGURE 11: The effect of contact time on the removal of chromium.

3.8. SEM Analysis of SAH. Figure 9 presents the SEM micrographs of starch, starch/AAc blend, and starch/AAc/KOH blend hydrogels. The surface morphologies of the hydrogels show different characteristics. The starch/AAc hydrogel exhibits a relatively rough and compact surface pattern in SEM images (Figure 9(a)), which might be due to the hydrogen bond attraction between the grafted $-\mathrm{COOH}$ chains. On the other hand, Figure 9(b) shows a relatively expanded structure in SEM images, which may be due to the repulsion between grafted $-\mathrm{COO}^{-}$chains with large electrostatic force. This expansion can facilitate the treated SAH to adsorb methylene blue. Bhuyan et al. [23] reported almost the same pattern of surface morphology for hydrogels.

3.9. Application of As-Prepared Hydrogels. Adsorption is one of the most important industrial mass transfer processes through which the dissolved components from an aqueous solution can remove by solid adsorbent to attract the dissolved solute towards its surface. The accumulation of concentrated matter at surface or the interphase is involved in this process. The liquid, solid, gas, or dissolved solute phase can exist in the adsorbent. The chemical adsorption occurred due to the exchange of electrons, where the adsorbate is chemically bonded to the surface. On the other hand, the physical adsorption occurred due to the attachment of adsorbate with the adsorbent surface by hydrogen bonding, Vander Waals forces, polarity, dipole-dipole interactions, etc. The above description notices extensive use in removing dyes or heavy metals from aqueous medium. The $\mathrm{pH} 6.5$ of prepared hydrogel was maintained for dye and chromium removal.

3.10. Application for Dye Removal. An additional important issue was to investigate the ability of SAH to remove hazardous methylene blue (MB) from IWW. Figure 10 illustrates the adsorption of methylene blue dye with different initial dye concentrations (20 to $60 \mathrm{ppm}$ ) as a function of standing time. It was found that dye adsorption increases with an increased initial dye concentration in an aqueous solution due to an increase of dye species in the bulk solution, 
TABLE 3: Adsorption capacity of hydrogels for $\mathrm{Cr}$ and $\mathrm{MB}$ dye removal.

\begin{tabular}{lccc}
\hline Adsorbent & $q_{\max , \mathrm{Cr}}(\mathrm{mg} / \mathrm{g})$ & $q_{\max , \mathrm{MB}}(\mathrm{mg} / \mathrm{g})$ & Reference \\
\hline AGMA-AAm-AAc hydrogel & 48.49 & & \\
Chitosan cross-linked hydrogel & 100 & 6.73 & {$[39]$} \\
N-Maleyl chitosan P(AA-Co-VPA) hydrogel & 66.89 & 40 & {$[40]$} \\
Tio2-graphene hydrogel graphite oxide & & 93.03 & {$[41]$} \\
Cellulose/chitosan hydrogel beads & & 5.93 & {$[42]$} \\
Chitosan-based hydrogel & 38.77 & 10.13 & This study \\
Potato starch/AAc/gamma radiation/KOH & 33.31 & $44]$ \\
Potato starch/AAc/gamma radiation & & & This study \\
\hline
\end{tabular}

increasing the possibility of dye contact with the gel. To capture $\mathrm{MB}$, the $\mathrm{SAH}$ was prepared by $5.0 \mathrm{kGy}$ gamma radiation dose that was optimized earlier. Furthermore, the dye adsorption capacity of THG was higher than that of UHG in every case. This is because the ionizing ability of the $-\mathrm{COOK}$ group is more than $-\mathrm{COOH}$ for the positively charged dye of MB. The maximum value is $38.95 \mathrm{mg} / \mathrm{g}$ of dye was removed by THG at an initial dye concentration of $40 \mathrm{ppm}$, indicating the possibilities for application in agriculture, pharmacy, and environmental technology.

3.11. Application for Chromium Removal. Hydrogels are excellent adsorbents to remove various types of metal ions from IWW [27]. This vital issue of the present study was to investigate the ability of SAH to remove hazardous chromium metal ions from industrial effluent water. The $40 \mathrm{ppm}$ concentrated chromium was removed by $5.0 \mathrm{kGy}$ of IWW as shown in Figure 11. Chromium adsorption was found to be higher for untreated SAH compared to the alkali-treated hydrogel. The reason is the low activity of $\mathrm{Cr}$ to exchange $\mathrm{K}$ instead of $\mathrm{H}$. The $\mathrm{Cr}$ adsorption attained maximum values around $10.13 \mathrm{mg} / \mathrm{g}$ at $3 \mathrm{~h}$ by UHG. Therefore, SAH can be considered as an alternative to low-cost adsorbent [34-38] for IWW treatment. The characteristics or efficiency values of SAH at $5.0 \mathrm{kGy}$ are listed in Table 2. Adsorption capacity of different hydrogels for $\mathrm{Cr}$ and $\mathrm{MB}$ dye removal is shown in Table 3. All experimental data of dye and Cr removal are reproducible and below $1.5 \%$ deviated.

\section{Conclusion}

Hydrogels were prepared from the aqueous solution of potato starch and AAc blend using gamma radiation, and a number of the hydrogels were treated with $\mathrm{KOH}$ in this study. The water absorption capacity of treated SAH is better than that of untreated SAH. It was also found that water absorption, swelling ratio, and equilibrium water content decrease with increased radiation dose. The optimum radiation dose is considered at $5.0 \mathrm{kGy}$ concerning gel fraction and swelling ratio. FTIR spectroscopic analysis spectra indicate the interaction of potato starch molecules with acrylic acid to form a hydrogel. Scanning electron microscopy (SEM) discloses that $\mathrm{KOH}$-treated hydrogels have expanded structures, which can facilitate the property of SAH to adsorb methylene blue from an aqueous solution. The pres- ent scenario is the maximum removal of $\mathrm{MB}$ is $38.95 \mathrm{mg} / \mathrm{g}$ by treated $\mathrm{SAH}$ at an initial dye concentration of $40 \mathrm{ppm}$. On the other hand, the chromium adsorption was higher by untreated $\mathrm{SAH}$ because of the low activity of $\mathrm{Cr}$ to exchange $\mathrm{K}$ instead of $\mathrm{H}$. The maximum adsorption attained for $\mathrm{Cr}$ was around $10.13 \mathrm{mg} / \mathrm{g}$ for $3.0 \mathrm{~h}$ by untreated SAH. Therefore, the SAH prepared in the present study was satisfactorily performed and proposed to be a practical application for IWW treatment enriched in organic dyes and heavy metals towards a safe environment.

\section{Data Availability}

All data generated through experiments and analyzed during this study are included within this article.

\section{Conflicts of Interest}

The authors declare no conflict of interest.

\section{References}

[1] J. M. Rosiak, "Radiation formation of hydrogels for drug delivery," Journal of Controlled Release, vol. 31, no. 1, pp. 9-19, 1994.

[2] K. M. Raju, M. P. Raju, and Y. M. Mohan, "Synthesis of superabsorbent copolymers as water manageable materials," Polymer International, vol. 52, no. 5, pp. 768-772, 2003.

[3] S. Sultana, M. A. Shariff, M. A. Hossain, A. Khatun, and R. Huque, "Effect of super water absorbent (SWA) hydrogel on productivity and quality of tomato," Archives of Applied Science Research, vol. 8, no. 10, pp. 5-9, 2016.

[4] S. Afroz, F. Afrose, A. K. M. M. Alam, R. A. Khan, and M. A. Alam, "Synthesis and characterization of polyethylene oxide (PEO) - N, N-dimethylacrylamide (DMA) hydrogel by gamma radiation," Advanced Composites and Hybrid Materials, vol. 2, no. 1, pp. 133-141, 2019.

[5] E. Manaila, G. Craciun, D. Ighigeanu, C. Cimpeanu, C. Barna, and V. Fugaru, "Hydrogels synthesized by electron beam irradiation for heavy metal adsorption," Materials, vol. 10, no. 5, p. 540, 2017.

[6] T. P. Sumanjit, S. Walia, and R. Kaur, "Removal of health hazards causing acidic dyes from aqueous solutions by the process of adsorption," The Online Journal of Health \& Allied Sciences, vol. 6 , no. 3, pp. 1-3, 2007. 
[7] E. Jabbari and S. Nozari, "Swelling behavior of acrylic acid hydrogels prepared by $\gamma$-radiation crosslinking of polyacrylic acid in aqueous solution," European Polymer Journal, vol. 36, no. 12, pp. 2685-2692, 2000.

[8] W. Xue, S. Champ, and M. B. Huglin, "Network and swelling parameters of chemically crosslinked thermoreversible hydrogels," Polymer, vol. 42, no. 8, pp. 3665-3669, 2001.

[9] E. Karadag, D. Saraydın, and O. Guven, "Radiation induced superabsorbent hydrogels. Acrylamide/itaconic acid Copolymers," Macromolecular Materials and Engineering, vol. 286, no. 1, pp. 34-42, 2001.

[10] D. Saraydın, E. Karadag, Y. Caldıran, and O. Guven, "Nicotine-selective radiation-induced poly(acrylamide/maleic acid) hydrogels," Radiation Physics and Chemistry, vol. 60, no. 3, pp. 203-210, 2001.

[11] M. W. Rutenberg and D. Solarek, "Starch Derivatives: Production and Uses. Starch: Chemistry and Technology (Second Edition), Chapter x-Starch Derivatives: Production and Uses," Food Science and Technology, vol. 1, no. 1, pp. 311-388, 1984.

[12] A. Charlesby, "Use of high energy radiation for crosslinking and degradation," Radiation Physics and Chemistry, vol. 9, no. 1-3, pp. 17-29, 1977.

[13] J. Singh, L. Kaur, and O. J. McCarthy, "Factors influencing the physico-chemical, morphological, thermal and rheological properties of some chemically modified starches for food applications-A review," Food Hydrocolloids, vol. 21, no. 1, pp. 1-22, 2007.

[14] H. M. N. El-Din, S. M. Badawy, and A. M. Dessouki, "Chelating polymer granules prepared by radiation-induced homopolymerization. I?Kinetic study of radiation polymerization process," Journal of Applied Polymer Science, vol. 77, no. 7, pp. 1405-1412, 2000.

[15] Y. Naka, I. Kaetsu, Y. Yamamoto, and K. Hayachi, "Preparation of microspheres by radiation-induced polymerization. I. Mechanism for the formation of monodisperse poly (diethylene glycol dimethacrylate) microspheres," Journal of Polymer Science: Part A Polymer Chemistry, vol. 29, no. 8, pp. 11971202, 1991.

[16] A. Chapiro, "Radiation induced polymerization," Radiation Physics and Chemistry, vol. 14, no. 1-2, pp. 101-116, 1979.

[17] P. Cheremisinoff, Handbook of Engineering Polymeric Materials, Taylor and Francis group, Boca Raton, Florida, USA, 1997.

[18] A. Alammar, R. Hardian, and G. Szekely, "Upcycling agricultural waste into membranes: from date seed biomass to oil and solvent-resistant nanofiltration," Green Chemistry, vol. 24, no. 1, pp. 365-374, 2022.

[19] K. Hemine, N. Łukasik, M. Gazda, and I. Nowak, “B-cyclodextrin-containing polymer based on renewable cellulose resources for effective removal of ionic and non-ionic toxic organic pollutants from water126286," Journal of Hazardous Materials, vol. 418, no. 1, 2021.

[20] E. Caló and V. V. Khutoryanskiy, "Biomedical applications of hydrogels: a review of patents and commercial products," European Polymer Journal, vol. 65, no. 1, pp. 252-267, 2015.

[21] T. B. S. Monir, S. A. R. A. Khan, M. Y. Miah, M. Takafuji, and M. A. Alam, "PH-sensitive hydrogel from polyethylene oxide and acrylic acid by gamma radiation," Journal of Composites Science, vol. 3, no. 2, p. 58, 2019.

[22] S. Sultana, M. R. Islam, N. C. Dafader, M. E. Haque, N. Nagasawa, and M. Tamada, "Effect of mono and divalent salts on the properties of carboxymethyl cellulose hydrogel under irradiation technique," International Journal of Chemical Sciences, vol. 10, no. 2, pp. 627-634, 2012.

[23] N. C. Dafader, N. T. Duoc, P. T. T. Hong, and D. Binh, "Synthesis and characterization of superwater absorbent hydrogel from cassava starch and acrylic acid blends by the application of $\gamma$-radiation," Caspian Journal of Applied Sciences Research, vol. 2, no. 1, pp. 1-10, 2013.

[24] N. C. Dafader, T. Akter, M. E. Haque, S. P. Swapna, S. Islam, and D. Huq, "Effect of acrylic acid on the properties of polyvinylpyrrolidone hydrogel prepared by the application of gamma radiation," African Journal of Biotechnology, vol. 11, no. 66, pp. 13049-13057, 2012.

[25] N. C. Dafader, M. N. Adnan, M. E. Haque, D. Huq, and F. Akhtar, "Study on the properties of copolymer hydrogel obtained from acrylamide/2-hydroxyethyl methacrylate by the application of gamma radiation," African Journal of Pure and Applied Chemistry, vol. 5, no. 5, pp. 111-118, 2011.

[26] M. Bhuyan, N. C. Dafader, K. Hara et al., "Synthesis of potato starch-acrylic-acid hydrogels by gamma radiation and their application in dye adsorption," International Journal of Polymer Science, vol. 2016, no. 1, pp. 1-11, 2016.

[27] D. Gokhale, I. Chen, D. Ian, and P. S. Doyle, "Micelle-laden hydrogel microparticles for the removal of hydrophobic micropollutants from water," ACS Applied Polymer Materials, vol. 4, no. 1, pp. 746-754, 2022.

[28] A. Alammar, S. H. Park, I. Ibrahim et al., "Architecting neonicotinoid-scavenging nanocomposite hydrogels for environmental remediation," Applied Materials Today, vol. 21, no. 1 , article $100878,2020$.

[29] X. Yu, J. Zhang, and Y. Zheng, "Perchlorate adsorption onto epichlorohydrin crosslinked chitosan hydrogel beads," Science of the Total Environment, vol. 761, no. 1, article 143236, 2021.

[30] Z. Wu, P. Zhang, H. Zhang et al., "Tough porous nanocomposite hydrogel for water treatment," Journal of Hazardous Materials, vol. 421, no. 1, article 126754, 2022.

[31] R. Bhat and A. A. Karim, "Impact of radiation processing on starch," Comprehensive Reviews in Food Science and Food Safety, vol. 8, no. 2, pp. 44-58, 2009.

[32] H. Lou, K. Wu, Q. Wang et al., "Forward osmosis with electroresponsive $\mathrm{P}$ (AMPS-co-AM) hydrogels as draw agents for desalination," Journal of Membrane Science, vol. 593, no. 1, article 117406, 2019.

[33] M. J. Alam, B. C. Das, M. W. Rahman, B. K. Biswas, and M. M. R. Khan, "Removal of dark blue-GL from wastewater using water hyacinth: a study of equilibrium adsorption isotherm," Desalination and Water Treatment, vol. 56, no. 6, pp. 1152011525, 2015.

[34] Q. Lv, Q. Hu, X. Zhang, L. Huang, Z. Liu, and G. Sun, "Highly efficient removal of trace metal ions by using poly(acrylic acid) hydrogel adsorbent," Materials \& Design, vol. 181, no. 1, article 107934, 2019.

[35] M. W. Rahman, M. Y. Ali, I. Saha et al., "Date palm fiber as a potential low-cost adsorbent to uptake chromium (VI) from industrial wastewater," Desalination and Water Treatment, vol. 88, no. 1, pp. 169-178, 2017.

[36] S. Parvin, M. W. Rahman, I. Saha, M. J. Alam, and M. M. R. Khan, "Coconut tree bark as a potential low-cost adsorbent for the removal of methylene blue from wastewater," Desalination and Water Treatment, vol. 146, no. 1, pp. 385-392, 2019. 
[37] M. Y. Ali, M. W. Rahman, M. Moniruzzaman et al., "Nypa fruticans as a potential low cost adsorbent to uptake heavy metals from industrial wastewater," Indian Journal of Applied Business and Economic Research, vol. 14, no. 2, pp. 1359-1371, 2016.

[38] M. Moniruzzaman, S. Kader, M. J. Alam, S. Aktar, A. Deb, and M. Khan, "Utilization of waste cigarette buds for the removal of reactive dye from wastewater," Journal of Engineering Research and Application, vol. 9, no. 2, pp. 2248-9622, 2019.

[39] A. T. Paulino, M. R. Guilherme, A. V. Reis, G. M. Campese, E. C. Muniz, and J. Nozaki, "Removal of methylene blue dye from an aqueous media using superabsorbent hydrogel supported on modified polysaccharide," Journal of Colloid and Interface Science, vol. 301, no. 1, pp. 55-62, 2006.

[40] W. Wang, H. Bai, Y. Zhao et al., "Synthesis of chitosan crosslinked 3D network-structured hydrogel for methylene blue removal," International Journal of Biological Macromolecules, vol. 141, no. 1, pp. 98-107, 2019.

[41] M. T. Nakhjiri, G. B. Marandi, and M. Kurdtabar, "Poly(AAco-VPA) hydrogel cross-linked with $N$-maleyl chitosan as dye adsorbent: Isotherms, kinetics and thermodynamic investigation," International Journal of Biological Macromolecules, vol. 117, no. 1, pp. 152-166, 2018.

[42] Y. Li, W. Cui, L. Liu et al., "Removal of $\mathrm{Cr}(\mathrm{VI})$ by $3 \mathrm{D} \mathrm{TiO}_{2}$-graphene hydrogel via adsorption enriched with photocatalytic reduction," Applied Catalysis B: Environmental, vol. 199, no. 1, pp. 412-423, 2016.

[43] M. Li, Z. Wang, and B. Li, “Adsorption behaviour of Congo red by cellulose/chitosan hydrogel beads regenerated from ionic liquid," Desalination and Water Treatment, vol. 57, no. 36, pp. 16970-16980, 2016.

[44] P. B. Vilela, A. Dalalibera, E. C. Duminelli, V. A. Becegato, and A. T. Paulino, "Adsorption and removal of chromium (VI) contained in aqueous solutions using a chitosan-based hydrogel," Environmental Science and Pollution Research, vol. 26, no. 28, pp. 28481-28489, 2019. 